\title{
ОСОБЕННОСТИ РАЗВИТИЯ ПРЕДПРИНИМАТЕЛЬСКОГО СЕКТОРА В УСЛОВИЯХ СТАНОВЛЕНИЯ ЦИФРОВОЙ МОДЕЛИ ЭКОНОМИКИ
}

\author{
(c) 2018 Коновалова Мария Евгеньевна \\ доктор экономических наук, зав. кафедрой экономической теории \\ Самарский государственный экономический университет \\ 443090, г. Самара, ул. Советской Армии, д. 141 \\ E-mail:mkonoval@mail.ru \\ (c) 2018 Фомин Евгений Пименович \\ доктор экономических наук, профессор \\ зав. кафедрой налогов и налогообложения, проректор по экономическому развитию \\ Самарский государственный экономический университет \\ 443090, г. Самара, ул. Советской Армии, д. 141
}

В статье рассмотрены проблемы развития предпринимательства в условиях цифровизации экономики, рассматривается трансформация содержания и сущности предпринимательской деятельности. Обосновываются рекомендации по реализации стратегии цифровизации в бизнес среду, устранения цифрового неравенства и обеспечения доступа к новейшим технологиям субъектов предпринимательской деятельности.

Ключевые слова: предпринимательство, бизнес, информатизация, цифровизация, институт предпринимательства.

Проблемы развития предпринимательского сектора представляются в настоящий момент весьма актуальными, особенно в эпоху трансформации традиционных представлений о ведении бизнеса, связанной с развитием и внедрением процессов цифровизации во все сферы жизнедеятельности человеческого общества. Формирования новой парадигмы экономического развития, обусловленного созданием принципиально новых инструментов и возможностей, вызывает необходимость всестороннего переосмысления как правовых, так и экономических аспектов предпринимательской деятельности.

В условиях глобальной цифровизации бизнеса меняются базовые представления о возможностях и способах получения прибыли, наибольшее значение в этих условиях приобретают стратегии риск доходности, скорости и безопасности совершаемых операций. Принятый Правительством РФ закон «О Стратегии развития информационного общества в Российской Федерации на 2017-20130 годы» заставляет научное сообщество по - новому взглянуть на многие устоявшиеся механизмы и модели координации хозяйствующих субъектов, в том числе субъектов предпринимательской деятельности. На смену вертикальному типу взаимодействия эко- номических акторов приходит горизонтальный, который практически стирает территориальные границы рынков, что обусловлено внедрением искусственного интеллекта, современных инструментов инвестирования, таких как краудфайдинг, краудлейдинг, ICO и т.п. Существенной тенденцией последних лет в области инвестиционной деятельности и принятия инвестиционных решений является внедрение облачных технологий, технологии блокчейн, Биг Дата, которые существенно снижают уровень не только трансакционных, но и трансформационных издержек. данные технологии позволяют создавать децентрализованные онлайн-сервисы на базе «умных контрактов». Блокчейн ускоряет процесс принятия инвестиционных решений в условиях взаимодействия с большим количеством контрагентов и позволяет повышать безопасность транзакций. Эксперты отмечают значительный рост используемых цифровых каналов связи в принятии и осуществлении инвестиционных решений различными участниками рынка. Так, например к 2020 году планируется проведение до 44\% всех инвестиций посредством мобильных каналов связи.

В современном понимании цифровая экономика представляет собой деятельность, в которой ключевым фактором производства являют- 
ся данные в цифровом виде, обработка больших объемов и использование результатов анализа которых по сравнению с традиционными формами хозяйствования позволяют существенно повысить эффективности различных видов производства, технологий, оборудования, хранения, продажи, доставки товаров и услуг. В этой связи следует признать, что в основу вышеописанной дефиниции заложены принципиально новые характеристика способов и методов осуществления предпринимательской деятельности.

Развитие цифровизации существенным образом экономит время предпринимателей на такие необходимые процедуры как регистрации предприятия, открытие расчетного счета, регистрация в налоговой службе и т.д. Внедрение информационных услуг, таких, например, как «Онлайн-запись на прием в инспекцию», возможности электронной подачи документов через МФЦ значительно снижают трансакционные издержки субъектов предпринимательской деятельности. Возможность электронной подписи всех учредительных документов несомненно ускоряет процесс регистрации и начала работы субъекта предпринимательской деятельности.

Процессы цифровизации создают новые виды экономической деятельности, результатами которой становится создание, например, электронной продукции: электронного оборудования, ПО, электронной аппаратуры, периодических изданий и т.д. Все большую популярность приобретает торговля в Интернет, а также использование такого сервиса как «интернет вещей».

Как нам видится, электронная коммерция также может быть рассмотрена как новый вид экономической деятельности в условиях становления цифровой экономики. Положительная динамика оборота продаж разнообразных товаров с помощью таких известных интернет-магазинов как Amazon, Apple-iTunes, «Озон» свидетельствует о росте привлекательности предпринимательства именно в этой сфере. Особенно интересным выглядит использование искусственного интеллекта в осуществлении сделок через интернет-магазины, который позволяет существлять такие тразакции от имени экономического агента, создающего данную интернет-платформу. Последние достижения в области строительства суперкомпьютеров позволяют приблизить их вычислительные возможности (около 1015 FLOPS) к возможностям головного мозга человека, вычислительная мощность которого оценивается приблизительно в 1020 FLOPS (FLOPS - количество операций с плавающей точкой в секунду). Не стоит путать ИИ с обычной автоматизацией. ИИ обладает очень важной отличительной особенностью он умеет менять алгоритм своей работы на базе данных, которые собирает. Причем эти изменения далеко не всегда запрограммированы логическими алгоритмами, а являются выводами, которые системы ИИ делают сами.

Использование цифровых технологий, а именно криптографии на финансовых рынках способствуют созданию еще одного принципиально нового вида предпринимательской деятельности - майнинга. Майнинг - это краеугольный процесс в сфере функционирования криптовалютной системы. Это вычислительный криптографический процесс создания новых блоков- цепочки записей, другими словами подтверждение транзакций. Сейчас майнинг контролируется большими пулами, с которыми мелкиемайнеры делятся своими ресурсами. Сеть зависит от операторов крупных дата-центров, многие из которых находятся в провинциях Китая, где электричество дешево. Майнеры в Китае, вложив большой капитал в майнинговые мощности, теперь имеют вычислительные «сверхспособности» для монополизации криптовалютного рынка. Для того, чтобы майнинг был признан видом предпринимательства необходимо его правовое закрепление. Следует сказать, что отдельные попытки такого закрепления уже предпринимаются. Так, уже рассматривается законопроект о регулировании цифровых финансовых технологий, в котором достаточно четко прописаны все основные понятия, связанные с развитием финансовых технологий в современной экономической системе.

Расширение использования инструментов цифровизации способствует упрощению взаимодействия хозяйствующих субъектов в ходе совершения экономических транзакций. Так, применение электронного документооборота ускоряет процесс закупки работ, товаров, услуг, что значительно сокращает время совершения сделок, и как, следствие, повышает эффективность производственной деятельности. Возможность осуществления электронных платежей оплаты товаров и услуг также обусловливает увеличение скорости происходящих процессов. Кроме того, все современные платежные элек- 
тронные сервисы достаточно надежны и обеспечивают высокий уровень безопасности.

Еще одной немаловажной проблемой реализации предпринимательской деятельности является обеспечение прав и законных интересов участников рынка. и здесь, на наш взгляд, необходимо создание и внедрение электронной системы правосудия, которая сможет эффективной, и главное, достаточно быстро рассматривать экономические споры, составлять необходимые акты, и давать грамотные заключения. Следует отметить, что в настоящее время уже проводятся эксперименты по внедрению отдельных элементов цифровизации в судебную практику. Так, в процессе судебных заседаний запись разговоров осуществляется с помощью специальной программы, распознающей речь и фиксирующей диалоги в электронном документе. Ранее, как известно, эту работу выполнял се- кретерь суда. Уже есть программы, которые могут рассматривать стандартные дела и выносить предварительное решение. Такие факты говорят о том, что в ближайшее время судебные заседания будут иметь виртуальный характер, где в качестве доказательств используются электронные документы, аудио -и видео записи, цифровые изображения, и т.д.

В заключении можно отметить, что трансформация парадигмы социально-экономического развития, обусловленная цифровизацией, неизбежно приводит к видоизменению предпринимательской деятельности, появлению ее новых форм, инструментов и способов координации. Расширение спектра предпринимательства обусловливает появление качественно нового императива развития, в основе которого лежит повышение уровня благосостояния общества.

\section{Библиографический список}

1. Стратегия развития Сбербанка до 2010 года [электронный ресурс] режим доступа: http://www.sberbank.ru/ common/img/uploaded/files/sberbankdevelopmentstrategyfor2018

2. Стратегия развития информационного общества в Российской Федерации (Утверждена Президентом Российской Федерации В.В. Путиным 7 февраля 2008 г. № Пр-212) Режим доступа: http://economy.gov.ru/ minec/activity/sections/infOrientedSoc/doc20080207_01

3. Бакиева М.Ю. Финансовые инновации в Российской экономике// Вестник СГСЭУ. 2018. № 3 (72). С. 16-19. 